\title{
ZAMBRANO, PILAR \& SAUNDERS, WILLIAM (eds.), UNBORN HUMAN LIFE AND FUNDAMENTAL RIGHTS, LEADING CONSTITUTIONAL CASES UNDER SCRUTINY, BERLIN, PETER LANG GMBH, 2019, PP. 264
}

\author{
Ligia de Jesús Castaldi ${ }^{1}$ \\ Recibido: 25 de junio de 2020 \\ Aprobado: 10 de julio de 2020 \\ Para citar este artículo: \\ Castaldi, L. de J.; Zambrano, P. \& Saunders, W. (eds.) (2020). \\ "Unborn human life and fundamental rights, leading constitutional cases \\ under scrutiny", Berlin, Peter Lang GmbH, 2019, pp. 264. \\ Prudentia Iuris, N. 90, pp. 21-23 \\ DOI: https://doi.org/10.46553/prudentia.90.2020.pp.21-23
}

La práctica del aborto nunca ha sido legalizada o convertida en un derecho a través de procesos verdaderamente democráticos: esta conclusión es frecuentemente sugerida por estudios de Derecho Comparativo sobre aborto y parece confirmarse en esta obra. El libro La vida humana prenatal y los derechos fundamentales: examen de casos constitucionales (Unborn human life and fundamental rights: leading constitutional cases under scrutiny) hace una crítica filosófica y legal de la manipulación de los procesos legislativos y el activismo judicial que han llevado a la legalización del aborto y su promoción, en once países democráticos del hemisferio occidental.

1 Professor of Law, Ave Maria School of Law, Naples, Florida, Estados Unidos. Correo electrónico: lcastaldi@avemarialaw.edu. 
El compendio de doce ensayos fue editado por William Saunders, Director de la Maestría en Derechos Humanos (M.A. in Human Rights), de The Catholic University of America, quien explica brevemente, para una audiencia internacional, la creación de un derecho constitucional al aborto por parte de la Corte Suprema de Estados Unidos en el caso Roe vs. Wade. Explica también las consecuencias del fallo en la deshumanización de la persona por nacer en el campo de la reproducción artificial, que elude regulación alguna en el Derecho norteamericano. También edita el libro la profesora de Navarra, Pilar Zambrano, quien hace un análisis moral de la jurisprudencia constitucional argentina sobre el derecho a la vida desde la concepción, particularmente del estatus de la persona por nacer en los fallos pro-vida de la Corte Suprema, Tanus y Portal de Belén, y posteriormente en el fallo F.A.L., que denomina "el primer fallo de la era del derecho de la madre a decidir".

La obra hace un análisis filosófico positivista y a la vez iusnauralista de la creación de un derecho constitucional a abortar en países de Europa, América Latina y el Commonwealth. Un selecto grupo de académicos en los campos de la Filosofía del Derecho contribuyen a esta obra; por ejemplo, el eminente profesor de Filosofía del Derecho en Oxford University, John Finnis; el profesor de Notre Dame Law School, Gerard V. Bradley y Salvatore Amato, de la Universidad de Catania (Italia). Los autores describen cómo las cortes supremas o cortes constitucionales de Italia, España y Estados Unidos han llegado a la creación de un derecho constitucional al aborto, aboliendo códigos penales y llevando a cabo enmiendas constitucionales a través de fallos o sentencias constitucionales. En el caso de Canadá, el profesor Dwight Newman explica cómo la opinión de una sola jueza, en la sentencia $R$. v. Morgentaler, fue entendida por la opinión pública como la creación de un derecho a abortar, a pesar de que la sentencia misma no lo hacía.

Respecto a América Latina, el profesor de Filosofía del Derecho de la Universidad de Navarra, Juan Cianciardo, escribe sobre el nefasto precedente de la sentencia de la Corte Interamericana de Derechos Humanos en el caso Artavia vs. Costa Rica, que negó la calidad de persona del embrión humano creado in vitro y del feto humano en base a una gradualidad según su estado de desarrollo. El profesor Hugo S. Ramírez García, de la Universidad Panamericana (México), describe los retos que enfrentan la mayoría de los estados mexicanos frente a las acciones constitucionales promovidas ante la corte suprema federal para abolir disposiciones constitucionales que protegen la vida de la persona por nacer, por ejemplo, en los estados de Oaxaca y Guanajuato.

Como señala John Finnis, en la conclusión del libro, la obra demuestra cómo la creación de un derecho al aborto en las jurisdicciones estudiadas ha evadido un verdadero escrutinio democrático y una apropiada aplica- 
ción de las reglas jurisprudenciales de interpretación constitucional. Ilustra también cómo aun cuando los procesos democráticos son formalmente invocados, la influencia de ciertas organizaciones políticas puede interferir con un verdadero resultado democrático del proceso, por ejemplo, en el caso del referendo convocado para revertir el reconocimiento constitucional del derecho a la vida de la persona por nacer en Irlanda. El antiguo Comisionado de Derechos Humanos irlandés, William Binchy, explica en su ensayo cómo el Tribunal Europeo de Derechos Humanos y el Comité de Derechos Humanos de las Naciones Unidas ejercieron enormes presiones sobre Irlanda para que revocara su protección constitucional de la vida prenatal, factor determinante en la organización del referendo y la formulación de la consulta misma.

Algunas excepciones demuestran que los altos tribunales son capaces de resistir presiones políticas a favor del aborto, como señala el magistrado Aleksander Stêpkowski, actual Juez de la Corte Suprema polaca, en un ensayo que especifica cómo la corte constitucional de ese país reconoció, en lugar de restringir, el derecho a la vida desde la concepción en la sentencia K26/96, revirtiendo la impunidad absoluta del aborto otorgada históricamente por la ocupación nazi y posteriormente por el gobierno comunista. Resalta también en América Latina el rechazo a la anticoncepción de emergencia por el Tribunal Constitucional del Perú en el año 2009 y de la Corte Constitucional de Chile en 2001, comentados respectivamente por los profesores Luis Castillo Córdova, de la Universidad de Piura (Perú), y Alejandro Miranda y Sebastián Contreras, de la Universidad de Los Andes (Chile).

El libro es sin duda una sólida fuente de información sobre la legalización internacional del aborto en el occidente, y por la autoridad académica de sus autores, también una importante crítica filosófica de la promoción internacional del aborto como un derecho humano. Esperamos que sea solo el primero de varios estudios filosófico-legales que revelen el déficit democrático del que sistemáticamente adolece la creación de un derecho legal al aborto, tanto con un enfoque iusnaturalista como positivista. 